bound to the metal at high $p \mathrm{H}$ in spite of the large negative charge on the chelate compound. The logarithms of the normal chelate stability constants for combination of the metal ion with the octa-negative anion were calculated as: calcium (II), 6.09; manganese (III), $9 \cdot 75$; copper (IT), $>10$; and iron (III), $>10$. It is apparent from the relative positions of the copper (II) and iron (III) titration curves that the chelate of the latter metal is considerably more stable. The stability is sufficiently high that a solution of the light yellow iron (III) chelate may be stored at a $p H$ of about 11 for a number of months without developing any sign of the precipitation of ferric hydroxide. The apparent stability of the iron (III) chelate compounds in alkaline solution indicates possible usefulness as an iron carrier.

This work was supported by the Dow Chemical Co., Framingham, Mass.

SONYA J. WESTERBACK

Arthur E. Martell

Department of Chemistry,

Clark University. Feb. 17.

${ }^{1}$ Schwarzenbach, G., Ackermann, H., and Ruchstuhl, P., Helv. Chim. Acta, 32, 1175 (1949)

${ }^{2}$ Bersworth, F. C., U.S. Pat. 2,599,807 (June 10, 1952).

\section{Polyaminopolycarboxylic Acids derived from Polyethyleneamines}

THE effects of increasing length of the alkylene bridge on acid dissociation constants and metal chelate stability constants of homologues of ethylenediaminetetra-acetic acid derived from polymethylenediamines have been reported within recent years ${ }^{1}$. The effects of an increase in the polydentate and polyelectrolyte nature of polyaminopolycarboxylic acids derived from polyethylene polyamines have not been investigated except for a brief report on diethylenetriaminepenta-acetic acid ${ }^{2}$. An investigation of diethylenetriaminepenta-acetic acid and triethylenetetraminehexa-acetic acid was therefore undertaken because of their relationship to ethylenodiaminetetraacetic acid.

The acids were prepared by the reaction of diethylenetriamine and triethylenetetramine with sodium cyanide and formaldehyde under alkaline conditions according to the procedure of Bersworth ${ }^{3}$. The free acids were separated from the alkaline reaction products by means of the hydrogen form of 'Dowex-50' on a column process. Concentration of the eluate gave the acids as white crystals which were purified by recrystallization from a minimum volume of hot water.

The acid dissociation constants of diethylenetriaminepenta-acetic acid and triethylenetetraminehexa-acetic acid were determined from potentiometric data at $25^{\circ} \mathrm{C}$. and $0 \cdot 1$ ionic strength (potassium nitrate) using a Beckman Model $G p \mathrm{H}$ meter. The equilibrium constants corresponding to the overlapping dissociation steps of the buffer regions were calculated by the graphical method of Schwarzenbach $^{4}$. The acids are tri- and tetra-dipolar ions respectively having the formulæ:
Neutralization of the pentabasic diethylenetriaminepenta-acetic acid occurs with one strong inflexion corresponding to formation of the tripotassium salt. Triethylenetetraminehexa-acetic acid, a hexabasic acid, exhibits two inflexion points: a weak inflexion occurring on the addition of three equivalents of potassium hydroxide and a welldefined inflexion corresponding to the formation of the tetrapotassium salt.

The acid dissociation constants are listed in Table 1 together with the values reported by $\mathrm{Kroll}^{2}$ for diethylenetriaminepenta-acetic acid.

Table 1. $p K$ Valogs of the Apparent Ionization Constants of DIETHYLENETRIAMINEPENTA-ACETIC ACID AND TRIETHYLENETETRAAMINEHEXA-ACETIC AOID AT $25^{\circ} \mathrm{C}$. IN $0.1 \mathrm{M}$ POTASSITM NITRATE

\begin{tabular}{|c|c|c|c|c|c|c|}
\hline Acid & $p K_{1}$ & $p K_{2}$ & $p K_{3}$ & $p \bar{K}_{4}$ & $p K_{3}$ & $p K_{\mathrm{e}}$ \\
\hline $\begin{array}{l}\text { DTPA } \\
\text { DTPA }^{2} \\
\text { TTHA }\end{array}$ & $\begin{array}{c}1 \cdot 79 \\
1 \cdot 90 \\
-\end{array}$ & $\begin{array}{l}2 \cdot 56 \\
2 \cdot 70 \\
2 \cdot 64\end{array}$ & $\begin{array}{l}4 \cdot 42 \\
4 \cdot 42 \\
4 \cdot 08\end{array}$ & $\begin{array}{r}8 \cdot 76 \\
10 \cdot 62 \\
6 \cdot 26\end{array}$ & $\begin{array}{r}10 \cdot 42 \\
12 \cdot 59 \\
9 \cdot 67\end{array}$ & $10 \cdot 82$ \\
\hline
\end{tabular}

- Determined at $25^{\circ} \mathrm{C}$. in $0.1 M$ potassium chloride

It appears that triethylenetetraminehexa-acetic acid is almost completely ionized at the concentration used in this study (approximately $3 \times 10^{-4} M$ ). Each compound possesses two strongly acidic carboxyl groups $\left(p K_{1}\right.$ and $\left.p K_{2}\right)$. The central ammonium groups are subject to the influence of the terminal positively charged ammonium groups. The net result of this configuration with its relatively high positive potential is an increase in acidity of the central ammonium groups as reflected in the values of $p K_{3}$ for diethylenetriaminepenta-acetic acid and $p K_{3}$ and $p K_{4}$ for triethylenetetraminehexa-acetic acid.

The behaviour of the acids with various polyvalent metal ions is now under examination. The increase in metal chelate stability constants and the ability to enter into bimetallic chelate formation arising from the increase in polydentate character indicate utiliza. tion of these compounds as metal carriers and metal buffers.

Albert E. Frost

Dow Chemical Co.,

Framingham, Mass. April 16.

1 Schwarzenbach, G., and Ackermann, H., Helv. Chim. Acta, 31, 1029 (1948).

${ }^{2}$ Kroll, H., Pinching, G., and Butler, F., Abst. 122nd Amer. Chem. Soc Meeting, Atlantic City, N.J., Sept. 14-19,6p (1952).

${ }^{3}$ Bersworth, F. C., U.S. Patent 2,407,645 (Sept. 17, 1946).

4 Schwarzenbach, G., Willi, H., and Bach. R. O., Helv. Chim. Acta, 30, 1303 (1947). 